\title{
Design of ATM Crime Monitoring System Based on MQTT Protocol Using SIM800L and Arduino Mega 2560
}

\author{
Intan Sugiyanti \\ Informatics and Computer Engineering \\ Politeknik Negeri Jakarta \\ Depok, Indonesia \\ intan.sugiyanti.tik15@mhsw.pnj.ac.id
}

\begin{abstract}
Banks as service providers have to behold to the security of ATM in various regions since CCTV and the existing security officers unable to overcome the problem of ATM damage or burglary maximally. ATM crime monitoring system was created to solve this problem by sending alarms and notifications in real time. The main focus of this paper is to define the data transmission on ATM crime monitoring system using MQTT. MQTT is used on the system as a protocol for sending data from the Arduino Mega 2560 microcontroller and SIM800L devices to the server. All data from various sensor will be sent in JSON format and Quality of Service $(\mathrm{QoS})$ used in MQTT is level 0. Data transmission using MQTT may filter normal conditions and alert conditions on ATM, data sent using 2 topics in order that the data can be used to send notifications and alarms in real time. In this research, SIM800L circuit configuration, SIM800L programming and MQTT protocol on Arduino IDE, and data transmission testing were carried out. The results of the research are that data transmission is successfully sent in real time and the filtered data is successfully divided into 2 conditions, namely under normal conditions and alert conditions. Further development can be done by replacing QoS with level 1 for the security of the data.
\end{abstract}

Keywords-MQTT, SIM800L, Arduino Mega 2560, Topic, Arduino IDE, HiveMQ, JSON

\section{INTRODUCTION}

Banks as institutions that provide services to their customers need to provide ATMs in various regions as one of the services that need to be fulfilled in order that customers could easily fulfill their banking transactions. In 2017 it was recorded that the number of ATMs in Indonesia was 103.918 units and that number sustain a quarterly increase [1]. The large number of ATMs in Indonesia has the potential to increase the number of crime rates at ATMs, in the period of 2011 to 2017, cases of ATM burglary with skimming continued to increase, in 2015 there were around 1.549 cases in Indonesia [2]. Prevention of ATM destruction does not work optimally due to long response times of events such as illegal actions that are difficult to monitor since there are no alerts or notifications to surrounding security personnel. Therefore, in an effort to overcome these problems a system was created that consists of various sensors and GSM / GPRS module (SIM800L) which functions to send sensor data in JSON format to a server with MQTT protocol QoS level 0 using Arduino Mega 2560 microcontroller. The data transmission used the MQTT protocol because the protocol has a response time and throughput that is faster than the HTTP protocol therefore the MQTT protocol is more suitable for IoT-based projects. The system can be used to conduct reporting and 24-hour monitoring or real time monitoring to prevent and reduce the risk of suspicious actions in an attempt to wreck an ATM machine.

\section{LITERATURE REVIEW}

\section{A. GSM/GPRS Module (SIM800L)}

SIM800L is used as data communication between server and client. SIM800L is a GSM module that could access GPRS for sending data to the internet with the M2M system. AT-Command used on SIM800L is similar to AT-Command for other GSM modules. SIM800L module has small dimensions therefore it is more suitable to be applied in designing portable devices. SIM800L has a Quad Band 850/900/1800/1900 MHz with small dimensions, namely size $15.8 \times 17.8 \times 2.4 \mathrm{~mm}$ and weight: $1.35 \mathrm{~g}$. SIM800L has a low power consumption with a power supply voltage range 3.4 $4.4 \mathrm{v}[3]$.

\section{B. Message Queuing Telemetry Transport (MQTT)}

Message Queuing Telemetry Transport (MQTT) is a protocol that runs on the TCP / IP stack and has a data packet size with a small low overhead (minimum 2 bytes) therefore that it has an effect on the consumption of power supplies which are also quite small. This protocol uses a publish / subscribe model rather than the client-server model. Publish / subscribe itself is a message exchange pattern in network communication where data senders are called publishers and data recipients are called subscribers. The TCP / IP stack is now supported by microcontrollers such as the STM32Fx7 series and general market devices such as Arduino Yun, Arduino+ Ethernet Shield, ESP8266 WiFi SoC, and Raspberry Pi [4].

The general MQTT system requires two main software components, namely [5] :

1. MQTT Client which will be installed on the device. For Arduino use publicclient, libraries such as mqtt.js can be used on the Node.js platform on Raspberry Pi or laptops.

2. MQTT Broker that functions to handle publish and subscribe to data. For the Node.js platform use the mosca broker, while for other platforms, there are many brokers, such as mosquitto, HiveMQ etc.

\section{MQTT Topic}

In MQTT, the term "topic" is in the form of UTF-8 string, which functions as a filter for brokers to send messages to each client that is connected, or in other words topic is a 
channel for subscribing clients. This topic will later determine which message the publisher must send to which subscirber [6].

\section{MQTT Quality of Service (QoS)}

One of the things that makes MQTT different is the high level of service or QoS. Therefore the published message must have one of the 3 QoS levels. These levels guarantee the reliability of sending messages. Clients and brokers provide a mechanism for storing and sending back messages therefore to improve data consistency due to network failures, restarting applications and other causes.

\section{Levels on MQTT are [7] :}

1. Level 0: The message is sent only once. The message sent depends on the TCP reliability stack or depends on the presence of the network and there is no attempt to transmit the message back.

2. Level 1: The message is sent at least once. Therefore the client will at least receive a message once. If the subscriber is not acknowledged, the broker will send a message until the publisher receives the message confirmation status from the client.

3. Level 2: The exact message is received once with four messages sent from the publisher to the gateway sequentially, namely publish, publish receive, publish release, and publish complete. This level of protocol ensures that messages are delivered and there is no duplication of messages sent.

\section{E. Arduino Mega 2560}

Arduino Mega 2560 is a microcontroller board based on ATmega2560. Arduino Mega2560 has 54 digital input / output pins, of which 15 pins can be used as PWM outputs, 16 pins as analog inputs, and 4 pins as UART (Serial Port Hardware), $16 \mathrm{MHz}$ crystal oscillator, USB connection, power jack, ICSP header, and reset button. Arduino Mega 2560 is compatible with most shields designed for Arduino Duemilanove or Arduino Diecimila. Arduino Mega2560 is the latest version that replaces the Arduino Mega version [8].

\section{F. Arduino IDE}

Integrated Development Enviroment (IDE) is an integrated environment that is used to carry out development. Referred to as the environment because through this software Arduino does programming to perform functions that are embedded through programming syntax. Arduino uses its own programming language that resembles $\mathrm{C}$ language. The Arduino (Sketch) programming language has been changed to make it easier for beginners to do programming from the original language. Before being sold to the market, the Arduino IC microcontroller has been implanted with a program called Bootlader which functions as an intermediary between the Arduino compiler and the microcontroller. Arduino IDE is made from JAVA programming language. Arduino IDE is also equipped with a $\mathrm{C} / \mathrm{C}++$ library commonly called Wiring which makes input and output operations easier. The Arduino IDE is developed from a processing software that is overhauled into a special Arduino IDE for programming with Arduino [9].

\section{SYSTEM ANALYSIS AND DESIGN}

\section{A. Overall System Design}

The crime monitoring system at the ATM is designed to monitor ATMs in real time to avoid physical crime such as hitting ATMs hard, dismantling ATMs, welding ATMs, burning ATMs, etc. The sensors used include smoke sensor, temperature sensor, tilt sensor, and shock sensor accompanied by RTC to find out the date and time of the incident and the buzzer as a notification in the event of a crime or alert condition, and CCTV to send video and images during an alert condition. . The data from the sensor and module will then be sent to the server using SIM800L using the MQTT protocol by dividing the topic into 2 namely "atm_normal" for normal conditions of all sensors and "atm_alert" for alert conditions of 1 or more sensors using the Arduino Mega microcontroller 2560. An overview of the system is explained in Fig 1.

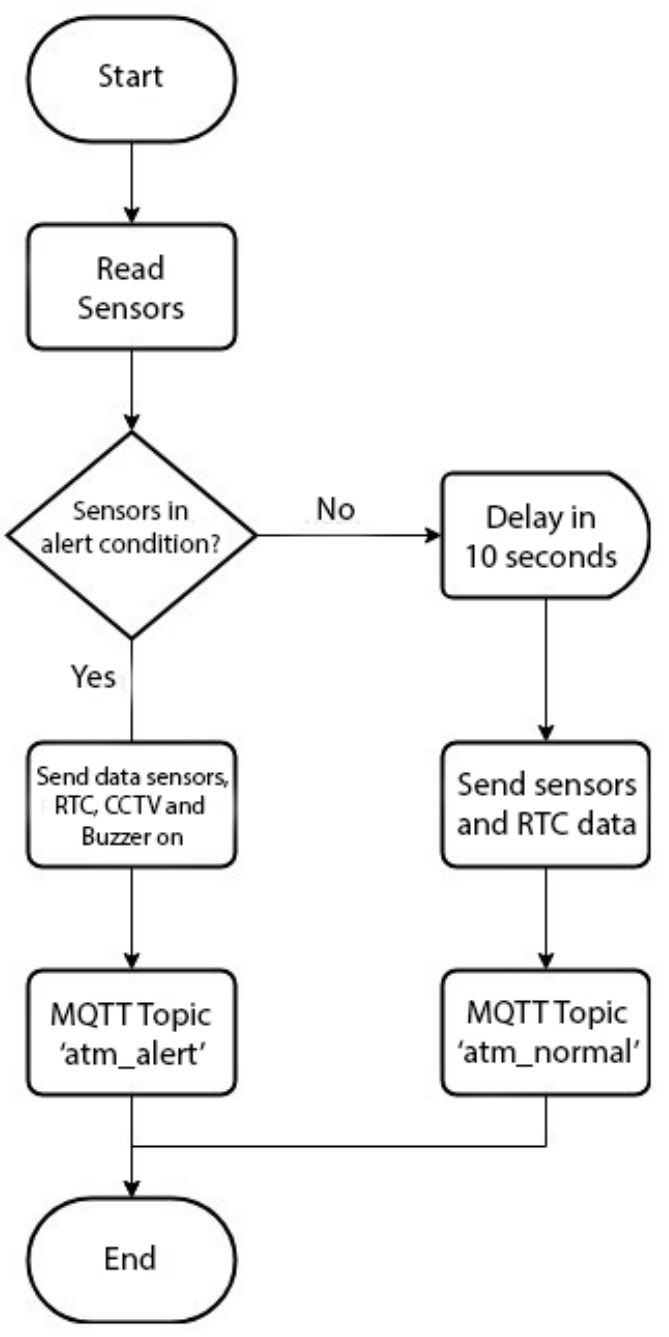

Figure 1. Crime monitoring system flowchart 


\section{B. SIM800L Circuit Configuration}

The tools used for SIM800L configuration are:

1. Stepdown Buck Converter

2. 9V-2A power supply adapter

3. SIM card

4. Jumper cable

5. Arduino Mega 2560

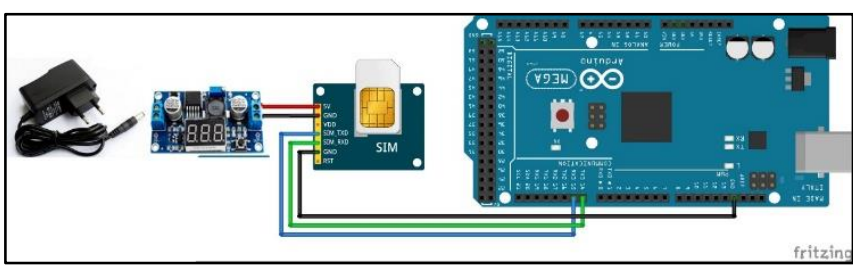

Figure 2. SIM800L Circuit Configuration

Set the power supply in the buck converter stepdown to $5 \mathrm{~V}$ before connecting it to SIM800L, using $5 \mathrm{~V}$ because when conducting experiments at voltage $3.7-4.2 \mathrm{~V}$ which matches the datasheet the SIM800L LED lights blink quickly which indicates that SIM800L is not getting a signal.

\section{SIM800L Programming on the Arduino IDE}

The configuration steps on the Arduino IDE are:

1. Download libraries for SIM800L and MQTT: The library used for SIM800L is TinyGsm while for MQTT, PubSubClient.

2. Initiation of libraries and pins on Arduino IDE.

3. MQTT broker configuration: The MQTT broker platform used is HiveMQ for testing.

4. Configuring the Access Point Name (APN): The SIM card used by SIM800L is with the XL provider.

- APN: Internet

- Username: [null]

- Password: [null]

5. Check SIM800L and MQTT connectivity.

6. Configuring data format: Data sent includes data ID, shock sensor, tilt, temperature, smoke, and RTC module which consists of time and date in JSON format as shown in Fig. 3.

\begin{tabular}{|c|c|c|}
\hline No. & Name & Data Format \\
\hline 1. & "ID" & "1234567890" \\
\hline 2. & "ShockStatus" & "SHOCK OFF"/ "SHOCK ALERT" \\
\hline 3. & "ShockValue" & $0 / 1$ \\
\hline 4. & "TiltStatus" & "TILT OFF" /"TILT ALERT" \\
\hline 5. & "TiltValue" & $0 / 1$ \\
\hline 6. & "GasStatus" & "GAS OFF" /"GAS ALERT" \\
\hline 7. & "GasValue" & $0-$ (limit belum diketahui) \\
\hline 8. & "TempStatus" & "TEMPERATURE NORMAL"/ \\
& & "TEMPERATURE ALERT" \\
\hline 9. & "TempValue" & 0-(limit dalam celcius belum diketahui) \\
\hline 10. & "Date" & "Tahun-Bulan-Hari" \\
\hline 11. & "Time" & "Jam:Menit:Detik" \\
\hline
\end{tabular}

Figure 3. JSON data format
7. Data transmission to MQTT broker / server: Data will be sent directly to the MQTT broker if an alert condition occurs and will be stored in the "atm_alert" topic, whereas if in normal conditions the data will be sent in a 10 seconds time interval and will be stored in the topic " atm_normal ".

\section{RESULT}

Tests on sending data to find out the results of a crime monitoring system at an ATM are carried out as follows:

1. Ensure that all sensor circuits, modules, and microcontrollers are correct and match the pins initiated on the Arduino IDE as shown in Fig. 4.

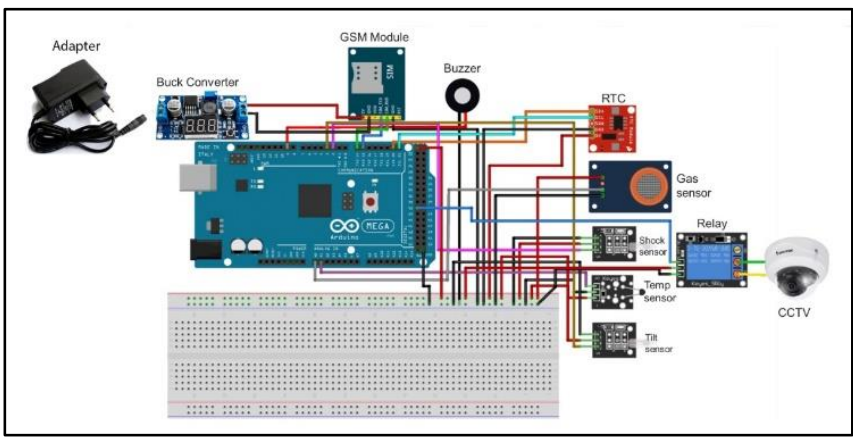

Figure 4. Overall system circuit

2. Open the MQTT broker using the HiveMQ platform (http://www.hivemq.com/demos/websocket-client/). Then make sure if the host matches the MQTT broker configuration on the Arduino IDE. Then select Connect.

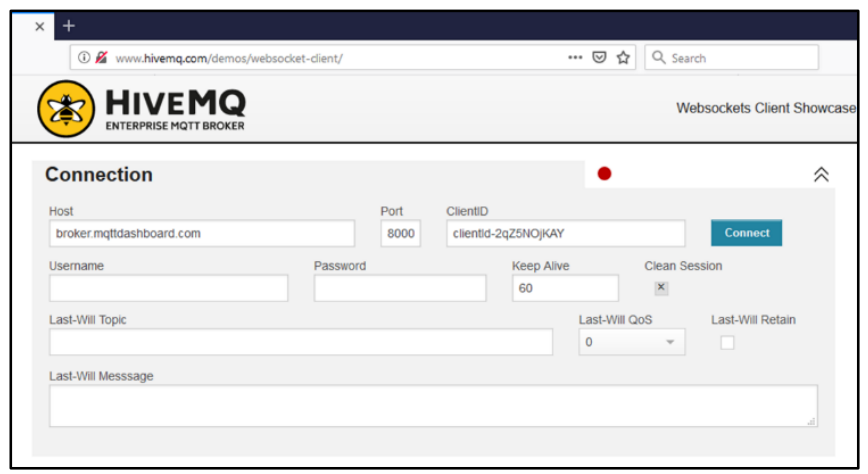

Figure 5. HiveMQ broker website

3. Click "Add New Topic Subscription" then create 2 topics namely "atm_alert" and "atm_normal" with the choice of QoS which is " 0 " and set the color as a difference between the 2 topics. Then select the Subscribe button.

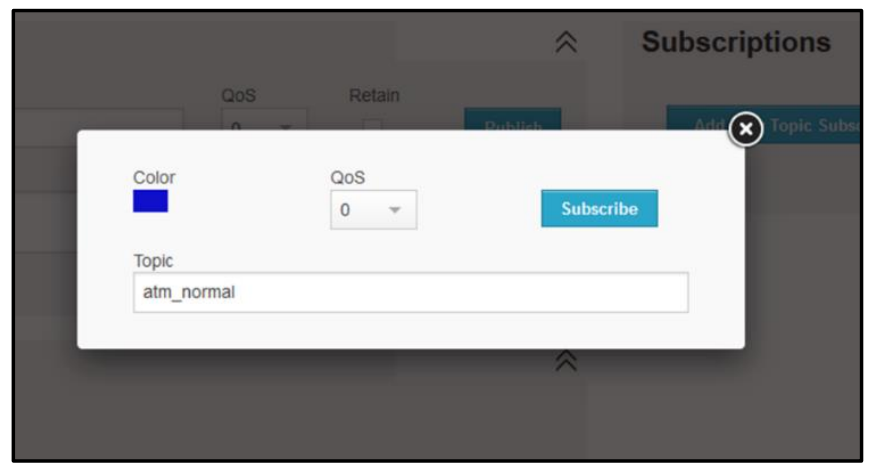

Figure 6. Making "atm_normal" topic 


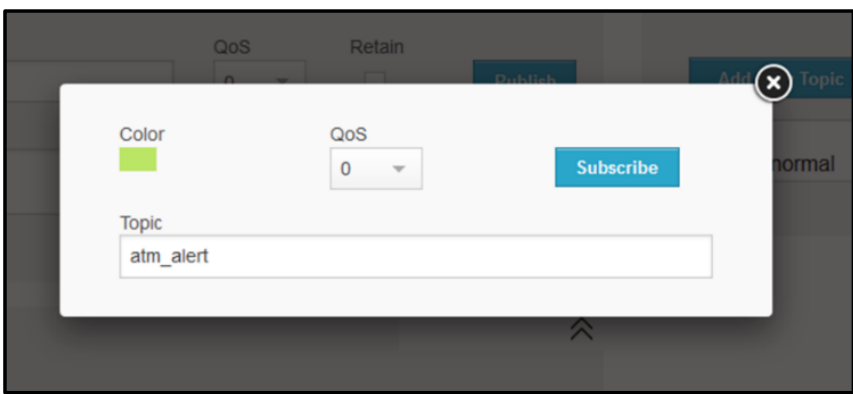

Figure 7. Making 'atm_alert' topic

4. Upload the source code contained in the Arduino IDE then select the serial monitor to find out the results of data transmission. Then compare it with the results on the HiveMQ platform. If the results are the same then sending data and filters to the topic has been successfully carried out.

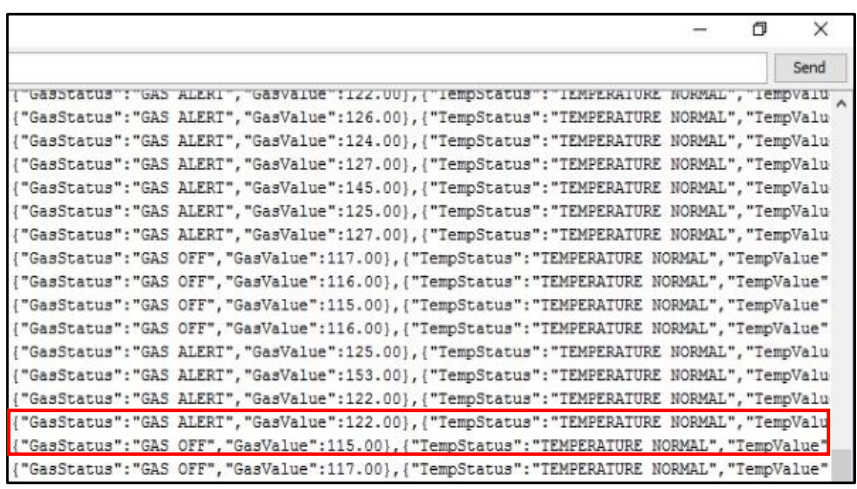

Figure 8. Results from serial monitor

["10"-1234567890"] ["ShockStatus" "SHOCK OFF" "ShockValue" 0]

("TiltStatus": "TILT OFF" "TiltValue". 0), ["GasStatus" "GAS

OFF" "GasValue" 115 00) ["TempStatus" "TEMPERATURE

NORMAL" "Tempvalue-25.33], [Date" "2018-11-27]),[Time":"14 10.4"]]

["ID" " 1234567890"] ["ShockStatus" "SHOCK OFF" "ShockValue" 0]

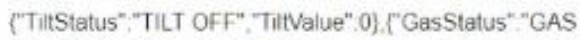

ALERT" "GasValue" 122.00) ["TempStatus" "TEMPERATURE

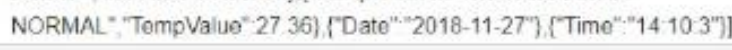

Figure 9. Result from HiveMQ

Fig. 8 and 9 show that data transmission was successfully carried out and successfully filtered between normal or 'atm_normal' conditions with alert conditions or 'atm_alert' in real time.

\section{CONCLUSION}

The problem of ATM burglary and destruction is still common in Indonesia, therefore in this study a crime monitoring system was created at the ATM to solve the problem in real time to make it easier for security officers to check the area around the ATM or help the police to arrest criminals. In this study the crime monitoring system at ATM managed to detect conditions around the ATM if in normal or alert conditions, the MQTT protocol can efficiently optimize and transfer data on data exchanges in the IoT system, the system can filter sensor and module data into 2 topics, namely "atm_normal" and "atm_alert", sending data from the sensor to the server was successfully carried out using SIM800L and the MQTT protocol with QoS level 0 in real time. As for suggestions for further research, namely for the security of data transmission using MQTT, it is recommended to use QoS level 1 therefore the data sent is not lost.

\section{REFERENCES}

[1] Syafina, D. C., 2018. Suatu Saat Nasabah Bank Tak Butuh Lagi Mesin ATM. [Online]. Available at: https://tirto.id/suatu-saat-nasabah-banktak-butuh-lagi-mesin-atm-cLn4. [Accessed 1 April 2019].

[2] Rahayu, R., 2018. Mengingatkan (Lagi) Praktik Pembobolan ATM dengan Skimming. [Online]. Available at: https://www.wartaekonomi.co.id/read173616/mengingatkan-lagipraktik-pembobolan-atm-dengan-skimming.html. [Accessed 1 April 2019].

[3] Affrilianto, R., Triyanto, D. \& Suhardi, 2017. Rancang Bangun Sistem Pelacak Kendaraan Bermotor Menggunakan GPS Dengan Antarmuka Website. Jurnal Coding Sistem Komputer Untan, V(3), pp. 1-11.

[4] Rochman, H., Primananda, R. \& Nurwasito, H., 2017. Sistem Kendali Bebasis Mikrokontroler Menggunakan Protokol MQTT pada Smartphone. Jurnal Pengembangan Teknologi Informasi dan Ilmu Komputer, June, I(6), pp. 445-455.

[5] Uditama, F. P., Primananda, R. \& Data, M., 2018. Perancangan Aplikasi Pemantauan Pendaki Gunung Menggunakan Wireless Network Dengan Protokol MQTT. Jurnal Pengembangan Teknologi Informasi dan Ilmu Komputer, May, 2(5), pp. 2102-2108.

[6] Rochman, H., Primananda, R. \& Nurwasito, H., 2017. Sistem Kendali Bebasis Mikrokontroler Menggunakan Protokol MQTT pada Smartphone. Jurnal Pengembangan Teknologi Informasi dan Ilmu Komputer, June, I(6), pp. 445-455.

[7] Hanifah, Sofi, A. S. R. \& Amron, K., 2018. Implementasi Quality of Service pada Protokol Message Queue Telemetry Transport - Sensor Network (MQTT-SN) Berbasis Arduino dan NRF24L01. Jurnal Pengembangan Teknologi Informasi dan Ilmu Komputer, 2(6), pp. 2131-2140.

[8] Arduino, 2017. Arduino Mega 2560 Rev3. [Online]. Available at: https://store.arduino.cc/usa/arduino-mega-2560-rev3. [Accessed 14 December 2018].

[9] Ilham, F. M., 2018. Mengenal Arduino UNO R3. [Online]. Available at: http://ilmuti.org/wp-content/uploads/2018/02/febby-muhammadilham_mengenal-arduino-2.pdf. [Accessed 14 December 2018]. 